\title{
Evaluation of Energy Efficiency with a Viewpoint to Urban Sustainable Development
}

\author{
Yujie Gao \\ Faculty of Maritime and Transportation \\ Ningbo University \\ Ningbo, China \\ gaosunlv@126.com
}

\author{
Yanhong Yin \\ Faculty of Maritime and Transportation \\ Ningbo University \\ Ningbo, China \\ yangyanh@yahoo.com.cn
}

\author{
ZhuoyuWang \\ Faculty of Maritime and Transportation \\ Ningbo University \\ Ningbo, China \\ wanzhuoyug@163.com
}

\begin{abstract}
This paper proposes a quantitative method to evaluate the energy efficiency of individual consumption behaviors. Energy consumption is determined by consumption of three kinds of goods: composite goods, car trips and mass transit trips. A model is developed to estimate the individual daily consumption of goods on the maximum utility level. Considering a consistency relationship between the utility level and energy consumption, energy efficiency index is developed to evaluate energy efficiency on different utility levels. We applied this method into a case study in Kumamoto City, Japan. High energy efficiency is found in populated urban area and places with high public transport accessibility. This founding gives robust support for urban sustainable development.
\end{abstract}

Key words-Energy efficiency, consumption behaviors, utility, urban sustainable development.

\section{INTRODUCTION}

More than half of the energy has been consumed in the last two decades since the industrial revolution, despite advances in energy efficiency. According to IEA (International Energy Agency) world statistics in four years (2004-2008), the world population increased 5\%, annual $\mathrm{CO}_{2}$ emissions increased $10 \%$ and gross energy production increased $10 \%$. The global warming emissions are the most serious global environmental problem caused by burning fossil fuel. Facing the increasing price of fuel, many nations are set up goals to reduce energy consumption to prevent a dangerous influence in the climate system.

Energy users are divided into four groups according to sectors of economy, residential, commercial, industrial, and transportation. Checking the ratio of energy consumption of each sector in the USA ${ }^{[1]}$, the transportation sector uses twenty-nine percent of the energy supply to move people and goods from one place to another. And residential sector account for $22 \%$ of energy use. The energy related to individual transportation and housing is a big contributor to energy consumption. Although industry and commercial sectors are not directly contributed to personal energy consumption, we do depend on the goods and services provided by these two sectors. As whole, all the activities of four sectors are for the needs of individuals. Thus energy consumption of society is determined by personal consumption behaviors. From a micro-view, energy consumption is closely related to the level of quality of life, which is decided by personal consumption behaviors ${ }^{[2]}$.

In this paper, we estimate the individual energy consumption on present level of quality of life, which is reflected by maximum utility. In the course of this paper, we will describe the methodology of estimating the individual energy consumption by consumption behaviors on maximum utility. Energy efficiency is presented as an index to compare the relative energy consumption on different utility levels. Then it is followed by the description and discussion of a case study in Kumamoto, Japan.

\section{METHDOLOGY}

Quality of life can be reflected by the utility according to economics theory ${ }^{[3]}$. In reality, people would like to choose different kinds of goods to achieve the maximum utility within limited income. Meanwhile, goods consumption is actually a process of energy consumption. More goods consumption means more energy consumption. So the goal of the model is to find the minimum energy consumption on present level of quality of life by consuming many kinds of goods.

\section{A. Modelling consumption behaviors}

As transportation sector is a bigger contributor to energy consumption, we classified all goods into two types: mobility goods and composite goods. Mobility goods include car trips and mass transit trips. Composite goods are all other goods except for mobility goods. Now the model problem transfers to how to estimate the minimum energy consumption on maximum utility and find the corresponding consumption pattern of these three kinds of goods.

Some assumptions are needed in order to formulate the model. 1) We assume that the representative individual in zone 
$i$ consumes three types of goods: composite goods and trips by car and mass transit. The demands are shown as $x_{1 i}, x_{2 C i}$, and $x_{2 M i}$, respectively. 2) The mobility goods $x_{2 i}$ is a function of the number of trips by car and mass transit. 3) Utility $u_{i}$, which reflects the level of quality of life, is defined as a function of these three kinds of goods. 4) Representative consumer in zone $i$ is assumed to maximize his/her utility and mobility by consuming different amount of goods under the income budget constraint. 5) All the income is spent on consuming goods without saving.

A two order CES (constant elasticity of substitution) function is chosen to express the utility. CES refers to a particular type of aggregator function that combines two or more types of consumption into an aggregate quantity ${ }^{[4]}$. A CES function is used to represent the constant elasticity of substitution between composite goods and mobility goods at the first order. The relationship of substitution between car trips and mass transit trips is represented by CES type function at the second order. The detailed expression of functions are shown in Eq. (1) and Eq. (2). $\sigma_{1}$ and $\sigma_{2}$ are the elasticity of substitution between two goods at the first and second orders. $\alpha_{1}$ and $\alpha_{2}$ are the share parameters of composite goods and mobility goods, while $\alpha_{2 C}$ and $\alpha_{2 M}$ are share parameters of car trips and mass transit trips, respectively.

We assume that people would like to maximize both utility and mobility. The consumption behaviors are expressed by the demand of goods on the maximum utility, which is calculated by solving two maximization problems. Posed as Eq. (1), the maximum mobility is determined by car trips and mass transit trips subject to transportation budget. The maximum utility is determined by consumption of composite goods and maximum mobility under the income constraint, posed as Eq. (2).

$$
\begin{aligned}
\max _{x_{i i}, x_{2 i}}: & u_{i}=\left\{\alpha_{1} x_{1 i}^{\left(\sigma_{1}-1\right) / \sigma_{1}}+\alpha_{2} x_{2 i}^{\left(\sigma_{1}-1\right) / \sigma_{1}}\right\}^{\sigma_{1} /\left(\sigma_{1}-1\right)} \\
\text { s.t. } \quad & p_{1 i} x_{1 i}+p_{2 i} x_{2 i} \leq I_{i}
\end{aligned}
$$

$$
\begin{gathered}
\max _{x_{2 C}, x_{2 M i}}: x_{2 i}=\left\{\alpha_{2 C} x_{2 C i}^{\left(\sigma_{2}-1\right) / \sigma_{2}}+\alpha_{2 M} x_{2 M i}^{\left(\sigma_{2}-1\right) / \sigma_{2}}\right\}^{\sigma_{2} /\left(\sigma_{2}-1\right)} \\
\text { s.t. } \quad p_{2 C i} x_{2 C i}+p_{2 M i} x_{2 M i} \leq I_{2 i}
\end{gathered}
$$

$p_{I i}, p_{2 i}, p_{2 C i}, p_{2 M i}$ are the price of composite goods, mobility goods, car trips and mass transit trips in zone $i$, respectively. $I_{i}$ is the individual income and $I_{2 i}$ is the individual transportation budget, each in zone $i$.

\section{B. Estimation of energy consumption}

The energy consumption can be calculated if the demand of three kinds of goods on the maximum utility are determined (Eq. (3)). $E_{i}$ is the individual energy consumption in zone $i . e_{l}$, $e_{2}, e_{3}$ are the energy consumption unit of composite goods, car trip and mass transit trip, which is indicated by the value of energy needed for per goods. $x_{1 i}{ }^{*}, x_{2 C i}{ }^{*}, x_{2 M i} *$ are the optimal demand of composite goods, car trips and mass transit trips on the maximum utility $u_{i}{ }^{*}$, respectively. Considering the relationship between energy consumption and traffic congestion, we introduce the average trip time of the car trip and mass transit trip $t_{2 C i}, t_{2 M i}$ into the estimation function, which are dynamic functions of trips.

$$
\begin{gathered}
E_{i}=e_{1} x_{1 i}^{*}+e_{2} t_{2 C i}\left(x_{2 C i}^{*}, x_{2 M i}^{*}\right) x_{2 C i}^{*}+e_{3} t_{2 M i}\left(x_{2 C i}^{*}, x_{2 M i}^{*}\right) x_{2 M i}{ }^{*} \\
u_{i}\left(x_{1 i}^{*}, x_{2 C i}^{*}, x_{2 M i}^{*}\right)=u_{i}^{*}
\end{gathered}
$$

\section{Energy efficiency index}

Energy efficiency index is developed to evaluate energy consumption efficiency of individuals of each zone. The indicator, $U E_{i}$, is calculated as Eq. (4). Higher value of $U E_{i}$ means less energy is consumed for achieving the same utility level. That also means higher energy efficiency.

$$
U E_{i}=\frac{u_{i}}{E_{i}}
$$

\section{APPLICATION}

We chose the Kumamoto metropolitan area for our study because of data availability. The Kumamoto metropolitan area is located in Kumamoto Prefecture on the island of Kyushu, southern Japan. Two cities (Kumamoto and Uto), fourteen towns, and one village are distributed in this region. The whole region covers roughly $1077 \mathrm{~km}^{2}$ of land and has a population of 970,375 (Kumamoto Metropolitan Region, 1997 Personal Trip Survey). The center of the region is Kumamoto city, which had a population of 645,675 and area of $276 \mathrm{~km}^{2}$ in 1997. The region is divided into 177 traffic zones. Among them, 88 zones are located in the Kumamoto city and 89 zones in the outside city area (Fig. 1).

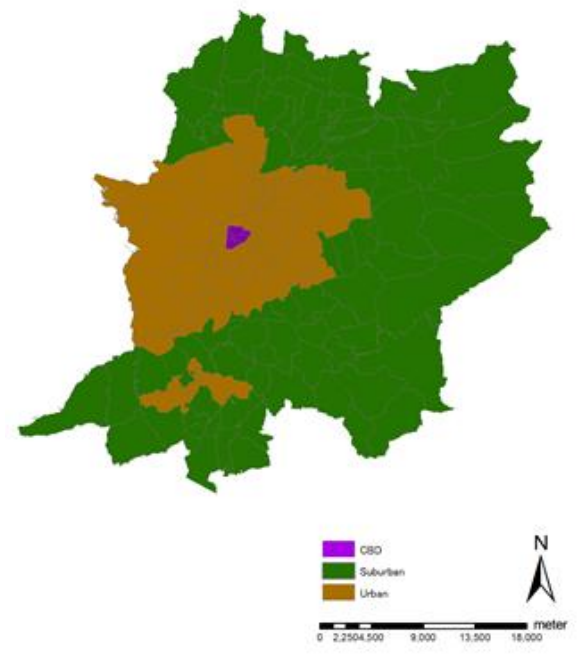

Fig.1 Kumamoto metropolitan area

\section{A. Parameter estimation}

We used the PTS data of Kumamoto to estimate these parameters. The results are shown Table 1 .

TABLE 1 ESTIMATED PARAMETER RESULTS IN KUMAMOTO

\begin{tabular}{|c|c|c|c|c|c|}
\hline$\sigma_{1}$ & $\boldsymbol{\sigma}_{2}$ & $\boldsymbol{\alpha}_{\boldsymbol{1}}$ & $\boldsymbol{\alpha}_{2}$ & $\boldsymbol{\alpha}_{2 C}$ & $\boldsymbol{\alpha}_{2 M}$ \\
\hline 1.213 & 0.437 & 0.478 & 0.522 & 0.981 & 0.019 \\
\hline
\end{tabular}




\section{B. Energy unit}

According to the statistic report by Japanese government [5], the energy unit of each composite good, car trip and mass transit trip is set as values in Table 2 .

TABLE 2 ENERGY UNIT OF GOODS IN KUMAMOTO

\begin{tabular}{|l|l|l|}
\hline $\begin{array}{l}\text { Composite good } \\
\text { (kal/person.day) }\end{array}$ & $\begin{array}{l}\text { Car trip } \\
\text { (kal/person.min) }\end{array}$ & $\begin{array}{l}\text { Mass tranit trip } \\
\text { (kal/person.min) }\end{array}$ \\
\hline 2.46 & 142.74 & 17.68 \\
\hline
\end{tabular}

\section{Estimated energy consumption}

More than $37200 \mathrm{kcal}$ of energy is estimated for each person in one day in Kumamoto. Among them, more than $73 \%$ of energy is used for composite goods consumption. $26 \%$ of energy is for car trips. Only less than $0.5 \%$ of energy is used for mass transit trips (Table 3). Based on the estimation results, large part of energy is spending on composite goods consumption, which is mainly for household residential and recreation uses. Energy of car trips accounts for big share compared to mass transit trips, indicating car travels is very popular and energy intensive.

TABLE 3 ESTIMATED ENERGY CONSUMPTION FOR ONE PERSON PER DAY

\begin{tabular}{|l|l|}
\hline Total energy consumption & $3.72 \times 10^{4}$ \\
\hline Energy consumption for composite goods & $2.72 \times 10^{4}(73.12 \%)$ \\
\hline Energy consumption for car trips & $9.87 \times 10^{3}(26.48 \%)$ \\
\hline Energy consumption for mass transit trips & $1.52 \times 10^{2}(0.41 \%)$ \\
\hline
\end{tabular}

(): Energy share of goods

\section{Energy efficiency}

We introduce the energy efficiency index to compare energy consumption on different utility levels of zones in Kumamoto. This index is analyzed at two levels: region and zone level, respectively. The regional energy efficiency index is the ratio of average utility and energy consumption for one resident in Kumamoto region. Table 4 lists the averaged utility, energy consumption, and energy efficiency in Kumamoto.

TABLE 4 AVERAGED UTILITY, ENERGY CONSUMPTION AND ENERGY EFFICIENCY IN KUMAMOTO

\begin{tabular}{|l|l|}
\hline Utility & 6966 \\
\hline Energy consumption & 37276 \\
\hline Energy efficiency & 0.187 \\
\hline
\end{tabular}

We also analyze the energy efficiency at zone level. Figure 2.a shows the estimated value of energy efficiency in each zone. While Fig. 2.b presents the main traffic network and population density in Kumamoto region. Although a few zones with higher energy efficiency are found in suburban and rural area, the energy efficiency decreases with the distance to the city center. Zones along the mass transit lines are higher energy efficient. a.

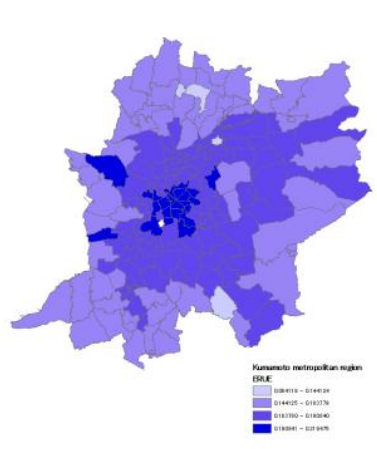

b.

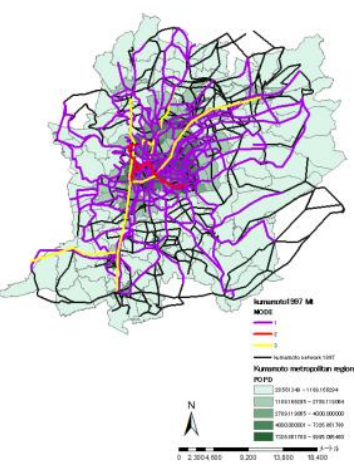

Fig.2.a Energy efficiency of zones in Kumamoto Fig.2.b Population density and traffic network in Kumamoto

\section{CONCLUSION}

V. This paper developed a model to estimate the energy consumption and utility based on individual consumption behaviors. An energy efficiency indicator was proposed to evaluate energy consumption efficiency of residents in different zones who are on several utility levels. By applying the method into Kumamoto, we found there is close relationship between the urban infrastructure configuration and energy efficiency. High energy efficiency zones mainly locate in dense area or along transport lines, especially mass transit lines. High population density and mass transit transport accessibility attribute to high energy efficiency. This founding gives meaningful suggestions for urban sustainable development.

\section{ACKNOWLEDGMENT}

This paper was supported by 2012 National Programs of Innovation and Entrepreneurship Training for Undergraduates in Ningbo University. This work was also supported by the K. C. Wong Magna Fund in Ningbo University.

\section{REFERENCES}

[1] U.S. Primary Energy Consumption by Source and Sector, the U.S. Energy Information Administration, 2009.

[2] Philips, D.: Quality of Life. Routledge, London, 2006.

[3] Stigler, G. J.: The development of utility theory: part 1 and 2. Journal of Political Economy 58, 307-27 and 373-96, 1950.

[4] Yin Y.H., Mizokami, S.S.. Evaluating compactness of cities by energy consumption efficiency. Journal of the Eastern Asia Society for Transportation Studies 9, pp. 713-723, 2011.

[5] Japanese Statistics Bureau of Ministry of Internal Affairs and Communications, http://www.e-stat.go.jp/SG1/estat.do. 